\title{
ELABORAÇÃO DE UM OBJETO DE APRENDIZAGEM PARA A PLATAFORMA ANDROID VOLTADO AO ENSINO E APRENDIZAGEM DE FÍSICA MODERNA E CONTEMPORÂNEA
}

\author{
Jhone Mendes de Almeida'; Gabriela Ribeiro Peixoto Rezende Pinto²; \\ Antônio Amorim Crispim Neto ${ }^{3}$ \\ 1. Bolsista PIBIC/CNPq, Graduando em Engenharia da Computação, Universidade Estadual de Feira de Santana, e-mail: \\ jhonedarts@gmail.com \\ 2. Orientador, Departamento de Exatas, Universidade Estadual de Feira de Santana, e-mail: gabrielarprp@ gmail.com \\ 3. Participante do projeto, Departamento de Tecnologia, Universidade Estadual de Feira de Santana, e-mail: \\ crispimneto2010@ hotmail.com
}

PALAVRAS-CHAVE: PBL; Física; Objeto de Aprendizagem.

\section{INTRODUÇÃO}

O processo de ensino-aprendizagem de Física presente hoje nas escolas de ensino fundamental e médio apresenta uma demanda, a inclusão de tópicos sobre a Física Moderna e Contemporânea (FMC).

No caso particular da Física, a atualização curricular tem levado a um movimento crescente de propor a inserção de conteúdos referentes à Física do século XX e início desse século, conhecidos como Física Moderna e Contemporânea. (LOCH; GARCIA, 2009).

Com uma necessidade crescente de apresentar estes "novos" conceitos da FMC que são raramente ensinados nas escolas do ensino médio/fundamental, são buscadas novas formas de acelerar e melhorar o ensino-aprendizagem. Um recurso que pode ser usado como apoio no processo de difusão e aprendizagem dos conteúdos da FMC são as Tecnologias da Informação e Comunicação (TIC). As TICs podem ser utilizadas para envolver os estudantes de maneira mais ativa na preparação de apresentações que lhes permitam materializar seu conhecimento e compreensão de diversos assuntos (BOSTER, MEYER, ROBERTO, INGE, \& STROM, 2006).

As TICs que auxiliam no ensino-aprendizagem podem ser consideradas Objetos de Aprendizagem (OA). O conceito de OA é variado, para este trabalho será adotado os seguintes conceitos: Qualquer entidade digital ou não digital que possa ser usada, reutilizada ou referenciada durante o uso de tecnologias que suportem o ensino (IEEE/LTSC, 2000) e também o conceito de que quaisquer recursos tecnológicos que possam ajudar no processo de ensino/aprendizagem e, além disso, serem reutilizados em um outro contexto, são considerados OA (TAROUCO; FABRE; TAMUSIUNAS, 2003).

Inicialmente, foram efetuadas pesquisas em acervos de artigos científicos em busca dos quais falassem de Objetos de Aprendizagem (OA) de qualquer gênero. Estas pesquisas dão noção do cenário atual dos softwares existentes que auxiliam no ensino-aprendizagem de Física Moderna e Contemporânea (FMC). As analises destas pesquisas como um todo, embasa a necessidade do desenvolvimento de um novo software.

As pesquisas foram feitas nas bases: SciELO (Livraria Eletrônica cientifica online), REDALYC (Rede de Revistas Cientificas da América Latina), SBIE (Sociedade Brasileira de Informática e Educação).

\begin{tabular}{|c|c|c|}
\hline \multicolumn{2}{|c|}{ Base SciELO; Filtros: Brasil, de 2009 a 2014, idioma português } \\
\hline Termos de pesquisa & Resultados encontrados & Resultados que contem OA \\
\hline Objetos aprendizagem & 37 & 6 \\
\hline Objeto aprendizagem & 80 & 4 \\
\hline Objeto educacional & 38 & 0 \\
\hline Objetos educacionais & 19 & 1 \\
\hline
\end{tabular}




\begin{tabular}{|c|c|c|}
\hline Totais & 174 & 11 \\
\hline Relacionados a Física & ------- & 2 \\
\hline
\end{tabular}

Tabela 1: Resultados Base SciELO.

\begin{tabular}{|c|c|c|}
\hline & Base SBIE; Anais de 2009 a 2013 \\
\hline Termos de pesquisa & Resultados encontrados & Resultados que contem OA \\
\hline Objeto & 79 & 76 \\
\hline Relacionados a Física & ---------- & 3 \\
\hline
\end{tabular}

Tabela 2: Resultados Base SBIE.

\begin{tabular}{|c|c|c|}
\hline \multicolumn{3}{|c|}{ Base Redalyc; Filtros: Filtros: Brasil, de 2009 a 2015, título e palavras-chave } \\
\hline Termos de pesquisa & Resultados encontrados & Resultados que contem OA \\
\hline Objetos aprendizagem & 0 & 0 \\
\hline Objeto aprendizagem & 0 & 0 \\
\hline Objeto educacional & 1 & 0 \\
\hline Objetos educacionais & 2 & 0 \\
\hline Totais & 3 & 0 \\
\hline Relacionados a Física & --------- & 0 \\
\hline
\end{tabular}

Tabela 3: Resultados Base Redalyc.

Após as análises dos 86 artigos encontrados que apresentam OAs, foi observado que apenas 5 deles se referem ao ensino-aprendizagem de Física, porém nenhum pertencente à FMC. Logo, fica visível que a FMC é uma área muito pouco explorada no quesito de OAs de ensino-aprendizagem.

Em iniciativa de suprir à esta demanda foi desenvolvido um OA voltado para o ensino de FMC para o ensino médio e fundamental intitulado "FisHQ", que se trata de uma hipermídia com uma sequência similar a uma história em quadrinhos.

\section{METODOLOGIA}

Em virtude da organização, versionamento e qualidade no desenvolvimento do OA, existem os modelos de engenharia de software. Eles tem a finalidade de propor um software bem estruturado respeitando os limites de prazo de desenvolvimento. Para este projeto, foram adotados aspectos específicos dos modelos Scrum e do Cascata, fazendo um merge entre eles.

O modelo Scrum, é um modelo ágil que permite a rápida e contínua inspeção do software em produção em intervalos de tempo periódicos (SOMMERVILLE, 2007). Este modelo apresenta esquema de reuniões periódicas, e é este o aspecto interessante para este projeto. O contato a um professor de Física nestas reuniões fornece um feedback muito importante para guiar o desenvolvimento.

O Modelo Cascata, segundo Sommerville, considera as atividades de especificação, desenvolvimento, validação e evolução, que são fundamentais ao processo, e as representa como fases separadas do processo, como a especificação de requisitos, o projeto de software, os testes e a implantação final compreendendo a manutenção. Deste modelo o aspecto interessante a este projeto foi a estrutura de fases, modificando o foco das discussões nas reuniões e desenvolvimento.

\section{RESULTADOS}

O software, OA, FisHQ, foi produzido pelo Grupo de Informática, Computação e Educação (GICE), situado no Laboratórios de Ciências Exatas (LABEXA) na Universidade Estadual de Feira de Santana (UEFS). Portanto trata-se de uma propriedade intelectual da UEFS 
contendo a licença de software livre, que se refere a qualquer programa que pode ser usado, copiado, estudado, modificado e redistribuído sem nenhuma restrição.

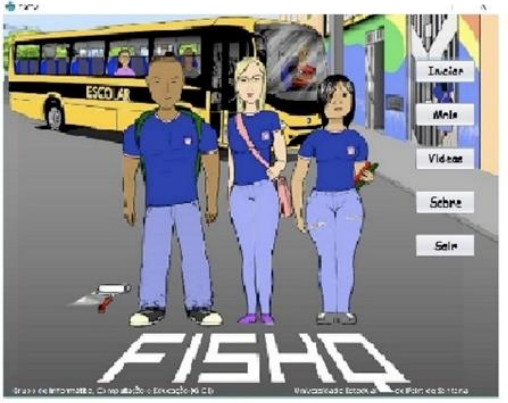

Figura 1: Tela Inicial

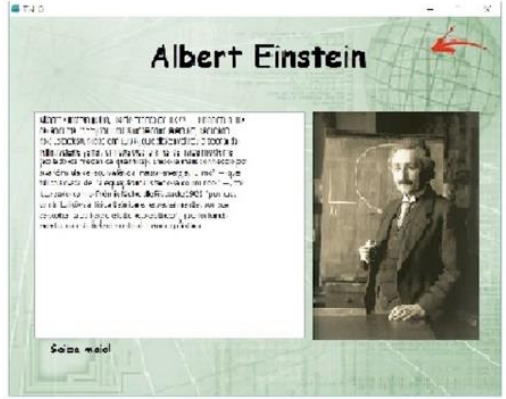

Figura 4: Albert Biografia

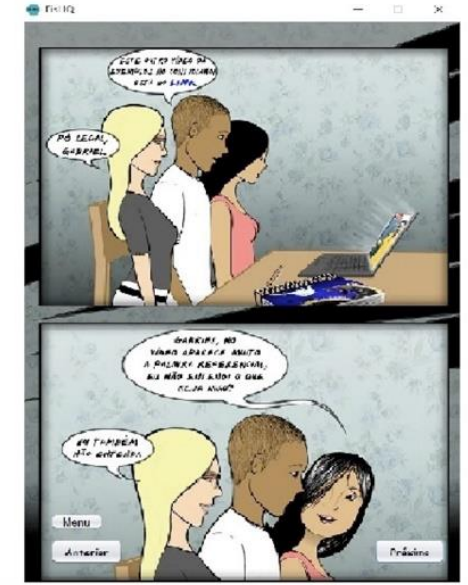

Figura 2: Sequencia em Quadrinhos

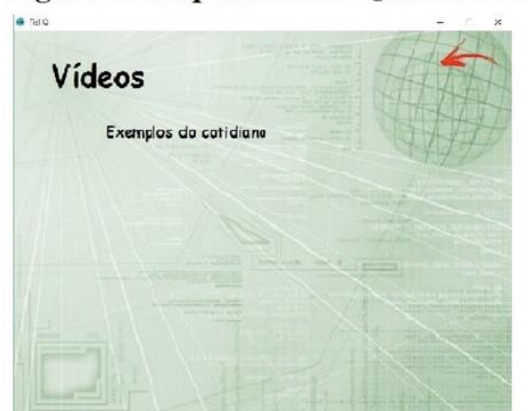

Figura 5: Tela "Videos"

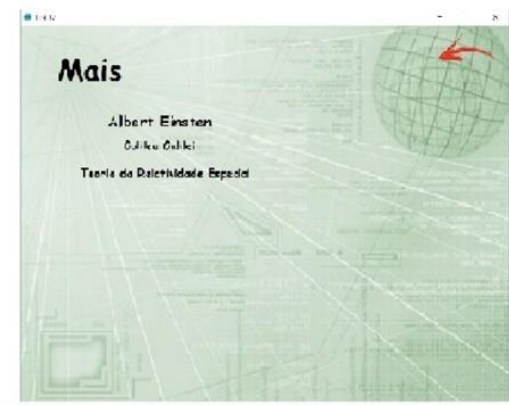

Figura 3: Tela "Mais"

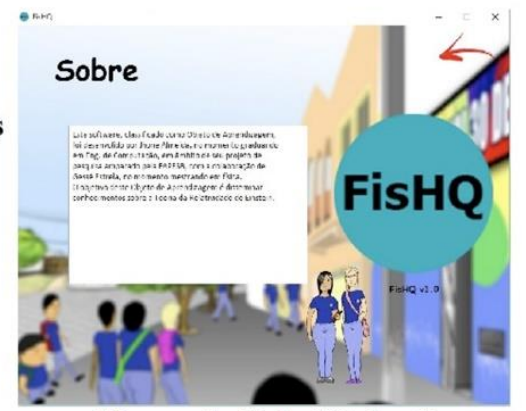

8

Figura 6: Tela "Sobre"

7

A figura 1 representa a intitulada Pagina principal, ou inicial. Representa o ponto de partida, tela com qual os usuários irão se deparar ao iniciar o programa. A partir dessa tela o usuário terá acesso a todos os módulos do programa, ou pode simplesmente sair clicando no botão "Sair" ou fechando a janela da aplicação.

A Figura 2 representa o módulo dos conceitos da Teoria da Relatividade em sequência de história em quadrinhos. Nesta tela é possível retornar à tela inicial pelo botão "menu", ou dar sequência à história. Neste contexto alguns hiperlinks podem surgir nas falas das personagens. Os hiperlinks deste modulo redirecionam às páginas do módulo "Mais" (figura 4), onde se deparará com uma breve biografia ou conceito.

A página "Mais", mostrada na Figura 3, representa o módulo de apoio à sequência da história em quadrinhos, acessada pelo botão "Mais" da tela inicial. A figura 4 representa uma tela informativa sobre determinado conceito ou pessoa, ela é acessada a partir da tela "Mais" (figura 3) e por hiperlinks do modulo de sequência em quadrinhos, como já foi citado.

A figura 5 mostra o acervo de vídeos do FisHQ. Os vídeos são reproduzidos usando utilizando o reprodutor padrão de vídeos da máquina que estiver executando. A figura 6 é uma tela informativa a respeito do software, o FisHQ.

\section{CONSIDERAÇÕES FINAIS}

A introdução de objetos tecnológicos no dia a dia do professor é hoje uma realidade. Os recursos tecnológicos propiciam vários incrementos nos recursos disponíveis, tanto no ensino presencial quanto na Educação a Distância (EAD).

No entanto, apesar da simbólica evolução, ainda é grande a carência de tecnologias que auxiliem no ensino-aprendizagem das escolas e instituições de ensino superior. É neste âmbito que as engenharias podem contribuir para a educação, produzindo ferramentas de auxílio à didática. 
O OA desenvolvido, auxilia no ensino-aprendizagem de conceitos introdutórios que se relacionam à Teoria da Relatividade. Possuindo uma linguagem de fácil entendimento, o que o torna mais acessível aos estudantes do ensino médio e/ou fundamental. Outro ponto é que possa ser usado a partir do software Problem Basic Learn - Virtual Software (PBL-VS II). Este ambiente virtual encontra-se em fase de desenvolvimento por uma outra linha de pesquisa da GICE, com o tema de dinâmica de resolução de problemas prevista no método PBL (Problem Basic Learn).

\section{Agradecimentos à \\ Prof $^{a}$ Dra. Gabriela R. P. R. Pinto, orientadora \\ Gessé Pinheiro, estudante do MNPEF \\ CNPq, órgão financiador}

\section{REFERÊNCIAS BIBLIOGRÁFICAS}

BOSTER, F. J., MEYER, G. S., ROBERTO, A. J., INGE, C., \& STROM, R. (2006). Some effects of video streaming on educational achievement. Communication Education, 55(1), 4662 .

IEEE-LTSC. Std1484.12.1 IEEE Learning Technology Standard Committee (LTSC) Standard for Learning Object Metadata (LOM), 2002.

LOCH, Juliana; GARCIA, Nilson M. D. Física Moderna E Contemporânea Na Sala De Aula Do Ensino Médio. VII Enepec, Florianópolis, 8 de novembro de 2009. Disponível em:<http://posgrad.fae.ufmg.br/posgrad/viienpec/pdfs/1335.pdf> Acesso:3 agosto 2016.

PINTO, G. R. P. R. ; SENA, C. P. P. ; COSTA, R. A. ; SILVA FILHO, S. S. ; PEREIRA, Hernane Borges de Barros . PBL-VE: Um ambiente virtual para apoiar a aprendizagem baseada em problemas.. In: XXXIX Congresso Brasileiro de Educação em Engenharia, 2011, Blumenau. Formação Continuada e Internalização. Blumenau: ODORIZZI, 2011.

SOMMERVILLE, I. Engenharia de Software. 8.ed. Rio de Janeiro: Pearson, 2007.Cap. 4

TAROUCO, L. M. R.; FABRE, M. J. M.; TAMUSIUNAS, F. R. Reusabilidade de objetos educacionais. RENOTE: revista novas tecnologias na educação - (fev. 2003). Porto Alegre: UFRGS, Centro Interdisciplinar de Novas 